\title{
Categories of distinction in programme planning
}

\section{Clara Kuhlen}

Julius-Maximilian University Würzburg, Germany (c-kuhlen@web.de)

\section{Regina Egetenmeyer}

Julius-Maximilian University Würzburg, Germany (regina.egetenmeyer@uniwuerzburg.de)

\begin{abstract}
The paper provides an analysis of the categories of distinction seized by programme planners in adult and continuing education and the underlying reasoning arguments to reasoning them. The analysis of 14 interviews shows that in their target group orientation, programme planners make use of the categories gender, migration experience, age, educational needs and dis/ability. The categories of distinction are based on their attribution as individual characteristics, as characteristics for grouping individuals, as characteristics of shared expectations and as occupation- and employment-related characteristics. The findings point to a need for encouraging awareness and critical reflection about categories of distinction.
\end{abstract}

Keywords: Categories of distinction, programme planning, target groups

\section{Introduction}

Programme planners in adult and continuing education are expected to recognise heterogeneity among participants (Tippelt \& von Hippel, 2018) and to take it into account when determining target groups in the course of developing educational offers (Robak, 2013; 2016). Heterogeneity is understood as social reality (Prengel, 2013; Walgenbach, 2017), and its recognition is considered a key perspective in the professional actions of adult educators (Tippelt \& von Hippel, 2018). When focusing on specific goals, winning

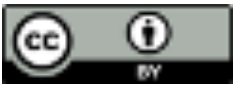


over participants, running a regionally specific needs assessment, or drafting programme descriptions, categories of distinction are used. Moreover, they are taken into consideration to define potential participants that may be addressed by the offers hereafter called 'addressees' - as well as target groups formed by shared characteristics and therewith may support the consideration of aspects of heterogeneity (Robak, 2016; Fleige et al., 2018; Gieseke, 2018a). The term "category of distinction" is being used to refer to normative perceptions and the social constructedness of differentiations. The orientation towards and determination of target groups hint to the processes of differentiation applied in adult education programme planning (Robak, 2013; 2016). The processes of differentiating are essential for programme planners in adult and continuing education, and they lead to the question which categories are used by them when determining target groups. Whereas the determination of categories differences and the work with them commonly applied in programme planning, very little empirical research is available on the patterns of reasoning that emerge in the process of constructing such target groups ${ }^{1}$.

Programme planning is understood as a complex process of alignment that is positioned inbetween various so-called "knowledge islands" (Gieseke, 2003). It is based in the configuration and negotiation of antinomies (von Hippel, 2011) and embedded in social, political institutional and organisational contexts, whilst the programme planners are asked to negotiate the interests and deal with the power structures in place (Cervero $\&$ Wilson, 1994). The positioning of programme planning comes along with the pluralist nature of adult and continuing education as an academic discipline (Gieseke \& von Hippel, 2018). Programme planners find themselves at an intersection where the negotiation is influencing the planning process as well as its outcome, the programme itself (Caffarella \& Daffron, 2013). On the one hand, promoting social participation is a key perspective in target group orientation (von Hippel et al., 2018). On the other hand, and aside from educational goals of adult education, programme planners must also meet the requirements of their organisations and their organisational environment, e.g. reaching certain target groups and ensuring a course's full capacity (von Hippel et al., 2018). Besides that, programme planners are asked to meet the societal requirement of promoting social participation amongst the participants, which, at the same time, is highly dependent on the participants' active participation (von Hippel, 2011). Not least, they must consider the individual expectations of participants that are incorporated in the target group orientation through anticipated needs of the participants (Gieseke, 2018b). Positioned at this intersection, programme planners negotiate the different functional logics of individuals, organisations, the environment, and society (Cervero \&Wilson, 1994; Fleige et al., 2018; Egetenmeyer et al., 2019). Taking these aspects as a charged relationship for the programme planners in mind, this paper examines the question about which categories of distinction are negotiated by programme planners in adult and continuing education. What reasoning is being used to legitimate the construction of these categories of distinction? The paper aims to analyse the categories of distinction in programme planning, considering the latter as a field of conflicting interests between the needs of target group determination and the related processes of attribution.

The approach of target group orientation in programme planning in adult and continuing education is taking into account how programme planners are guided by categories of distinction when planning adult education programmes (chapter 2). The focus on differences as markers of distinction when determining target groups underscores the constructedness of categories that are based on processes of Othering 
(chapter 3). Building on the results of a study obtained through a situational analysis of 14 interviews with programme planners in adult and continuing education (chapter 4), the categories of distinction used in the determination of target groups (chapter 5) are discussed against the background of how making programme planners aware of such categories of distinction may encourage them to reflect on their actions (chapter 6).

\section{Categories of distinction and processes of Othering}

Categories of distinction are connected to normative ideas, constructed differences and attributed differences. Normative ideas and its constructions refer to conceptions of normality (Ashcroft et al., 2013) that are also prevalent in adult education. They are evident in conceptions such as 'heterogeneity, social classes, milieus, addressees, target groups (women, elderly people, socially disadvantaged people, unemployed, people with dis/abilities, foreigners and migrants), educational equity, inclusion' (Robak, 2013, p. 185). Programme planners draw on these conceptions as didactical perspectives.

The underlying idea of the construction of categories of distinction is based on an understanding of Othering processes, drawn from postcolonial and poststructuralist approaches. Referring to Lacan (1968) the social fabric is characterised by a distinction between the "Self" and the "Other" wherein the "Other" as being different from the "Self" leads to distinctions that are expressed in categories. The latter hint to the attribution of identities of "Others", who are then labelled as individuals or groups. Building on Stuart Hall's (2002) conceptualisation of identity, the ascription of belonging people to an alleged group is a key part of Othering processes. As such, they involve mechanisms of inclusion and exclusion. Moreover, the process is influenced by a charged relationship between self-attributed characteristics and those that are ascribed by others. Categories of distinction as the presumed 'essence of individuals' (Robak, 2013, p. 185) have increasingly been discussed since the turn of the millennium (Lutz \& Wenning, 2001; Baader, 2013; Walgenbach, 2017). In a sociologist and interactionist perspective, they emerge in interactions and are constituted in situation-based attributions (Zifonun, 2018). Given the background that programme planning is highly influenced by the determination of target groups and groups of addressees, the need for critical reflection on the action of labelling people as belonging to specific groups based on categories of distinctions becomes apparent.

Raising the awareness that categories of distinction consist of a constructed character points to the necessity for critically reflecting on how differences are connoted. The multiplicity of connotation varies and may for example reflect negative tendencies, such as deficits that might be addressed, or, for instance, positive tendencies, such as diversity being embraced, and likewise other connotations. In this effort, it is important to engage in ongoing reflections, both concerning the orientation towards a participants' orientation as well as concerning one's own position by critically reflecting the power structures in place. Critical reflection is also required to determine whether target groups are defined based on categories of distinction that are driven by dichotomies. Promoting social participation and a positive recognition of differences can be achieved by addressing different target groups and meeting their expectations. At the same time, a deficitorientation must be problematised when critically considering the attribution of categories of differences. This leads to the question, which attributions and categorisations are evolving from differentiations made in programme planning processes? In adult and continuing education, these aspects are only partially researched, but are holding a 
potential for further analysis, historically positioned between pedagogy of differences and intercultural pedagogy (Baader, 2013).

\section{Methods and data basis}

The present analysis of categories of distinction in programme planning is a follow-up analysis of the findings of a study (Kuhlen, 2021) that examines how programme planners use categories of distinction. It is based on the approach of a situational analysis by Clarke (2012) that is methodologically located as grounded theory after the postmodern term and makes use of cartographic mapping strategies in order to address complexities in social contexts (ibid.).

The aforementioned study analyses semi-structured interviews conducted with 14 programme planners in adult and continuing education. The underlying assumption is that the professional practice of programme planning is highly complex, a fact that is evident in, among other things, the mutual effects of different antinomies (von Hippel, 2011). In order to reveal processes of differentiation on the part of programme planners, the interviewer encouraged narrations, used dialogical sequences, and asked follow-up questions. The partially pre-structured interview guideline was supplemented by openended questions over the course of the interview to allow for an emphasis on process and dialogue (Witzel, 2000). The process of data collection and the process of analysis was accompanied by memos (Clarke, 2012).

The sample includes interviewees from the German states of Baden-Wuerttemberg, Bavaria, Rhineland-Palatinate and the Swiss canton of Aargau. Interviewees were recruited with the help of flyers and by snowball effect. With one exception, all interviewees have a university degree in education; twelve of them with a focus in adult education. At the time of the interview, they were employed at eight different institutions, including local public institutions, universities, Roman Catholic institutions and private for-profit continuing education providers. After 14 interviews, the data collection process was purposely ended since sufficient material for a detailed analysis was collected in order to meet the category characteristics to answer the research question proposed in the doctoral dissertation (Kuhlen, 2021) for which the data was collected.

In the scope of the underlying study (Kuhlen, 2021), the situational analysis, informed by methodological aspects of grounded theory (Clarke, 2012), was used to create a project map, illustrating processes of differentiation in programme planning.

For this purpose, the author (Kuhlen, 2021) analysed the elements of participants, instructors, organisations and programme planners themselves, as well as non-human elements such as the digital/printed programmes consisting of various courses. By determining the relationships between those elements, conceptual links were drawn in order to identify key social worlds (Clarke, 2012) that are crucial to the analysis of the situation. Within these social worlds, categories of distinction were constructed in different ways. The reconstructed attributions of the categories of distinction refer to the patterns of reasoning that inform differentiation processes in programme planning.

The present paper analyses these patterns of reasoning, focussing on target group orientation in adult and continuing education. By analysing processes of negotiation and alignment, the importance of differences as constructed and hence categories of distinction in programme planning emerges as the main result of the analysis. For the present paper, this methodological approach allows for a comprehensive view of the situation in terms of the construction of categories of distinction as it pertains to the identification of target groups. The results are then consolidated with respect to the 
categories of distinction identified in the situational analysis. This consolidation shows how the problem is embedded in the identification of target groups. Using situational analysis as the guiding approach thus allows for identifying patterns of reasonings and reconnecting them to the discourse on the identification of target groups based on categories of distinction and the way they are embedded in programme planning. Drawn from an intersectional perspective, it is possible to reconstruct patterns of reasoning that go beyond the identification and attribution of individual categories of distinction. Therefore, the following chapter entails an analysis of categories of distinction while focussing on the identification of target groups as a key role in programme planning.

\section{Categories of distinction in the identification of target groups in programme planning}

Based on attributions of differences, the educational offers within a programme are (further) developed. The categorisations are created in line with a target group orientation and aim to create group-specific offers. Potential groups of participants are formed and the criteria for the development of educational offers are therewith sharpened. The categories of distinction reveal information about the process of attributing people to certain groups in the process of developing educational offers. These attributions are enabled by the actions of the programme planners. As a result, the work of programme planners involves assigning individuals and groups to different categories.

The various ways in which categories of distinction are differentiated suggest underlying patterns of reasoning that shape the prevalent distinctions in programme planning. Based on the results of the aforementioned situational analysis (Kuhlen, 2021), a closer look will be taken at five categories of distinction and their patterns of reasoning in the following chapters. A description of the attributions of categories of distinction (5.1) is followed by an analysis of the patterns of reasoning at work in this attribution (5.2) with respect to a target group orientation.

\section{Attribution of categories of distinction}

Reconstructing the ways in which categories of distinction are attributed mirrors the multifacetedness of how the categories of distinction are considered in programme planning. The categories gender, age and migration experience are addressed in a multiplicity of ways, indicating the importance that the interviewees assign to them in their programme planning. In addition, the attribution of educational attainment and dis/ability can be reconstructed from the interview data. Those categories of distinction are quite similar to the lines of difference already discussed in the current discourse (Allemann-Ghionda, 2013; Robak, 2013), being sex and gender, age, dis/ability, sociocultural affiliation and socioeconomic status. At the same time, previous analyses of these categories of distinction, such as gender- or migration-specific studies, have primarily focussed on each of the categories specifically rather than on their interrelations.

The prominent role of categories of distinction in programme planning varies in different contexts of programme planning. Interviewees' statements about the category of distinction gender, for example, appears to be strongly distinctive: 'to convince women and men of the virtues of the Academy' (interview 10, 11. 346, cited in Kuhlen, 2021; all subsequent citations from the same source unless otherwise noted). Regarding the category age, the distinctiveness is less pronounced. Target groups are referred to as 'children, youth, families, cross-generational', for example (interview 14, 1ls. 260-261.). 
Target groups with migration experiences are described as 'participants who, yes migrants, who come to Germany' (interview 7, 1ls. 129-130).

Furthermore, interviewees also address another category of distinction, educational attainment, albeit less distinctively: 'this is for a very different group of participants [...] a kind of educated bourgeoisie [...] but I am unsure whether it is still possible to call a group by that name' (interview 10, 1ls. 169-174). In this case, interviewees qualify and reflect on their own construction of difference while also retaining it to define the group of participants. Likewise, the category dis/ability is less distinctively found in the interview data: "we repeatedly see that we have people on board, including participants, who are special in some way [...] and we also have people in all other areas who have some kind of disability' (interview 6, 1ls. 501-502). Again, this category of distinction is attributed primarily to participants. Given that these two categories of distinction are not found in sufficient detail in the interview data, they will not be taken into further consideration in the following analysis of this paper.

The reconstruction of the categories of distinction shows how target groups are differentiated and highlights their role in programme planning. The categories gender and age are good examples of how categories of distinction are used as a marker of shared expectations: 'I think that seniors simply want to stay active longer, that they are fitter and more enthusiastic than they used to be, and that they do not see themselves as the typical stay-at-home seniors; so courses for seniors are very popular' (interview 8, lls. 604-609). The target group of seniors refers to age as the category of distinction. The interviewee groups seniors as a target group for their specific educational offers, anticipating an increase in their general fitness and a desire for activities as their expectations. Contrasting the seniors' different levels of activity and problematising this view as stereotypical, the interviewee goes on to differentiate the alleged expectation of this group. By pointing out the great utilization of these courses, the development of target group-specific offers based on the category age is seen as a positive. The fact that categories of distinction are seen as markers of shared expectations is also evident when reconstructing another category of distinction, gender, which guides programme planners in developing educational offers:

We start marketing a classical topic such as presenting or something like that for specific subgroups: how do I present as a project manager, how do I present as a buyer, how do I present for women et cetera et cetera [...] we try to bring specific groups together to be able to better serve these specific expectations (interview 13, 1ls. 773-785)

By naming three target groups, the interviewee distinguishes between project managers, buyers and women in terms of their anticipated needs in the field of professional development. Women are identified as a target group based on gender as a category of distinction. This distinction guides the interviewee in their actions and informs the programme planners' development of educational offers. The distinction is justified by referring to group-specific expectations. This target group-specific attribution of potential expectations is reconstructed as an anticipation of needs, based on the theoretical distinction between needs (Bedarfe) and expectations (Bedürfnisse) (Gieseke, 2018b).

\section{Patterns of reasoning for the attribution of categories of distinction}

Four patterns of reasoning can be identified in the attribution of categories of distinction. These patterns provide information about the background on which categories of 
distinction are used in programme planning in order to define target groups in the course of developing educational offers:

1. Categories of distinction as individual characteristics

2. Categories of distinction as characteristics for grouping individuals

3. Categories of distinction as characteristics of shared expectations

4. Categories of distinction as occupation- and employment-related characteristics

In the first pattern of reasoning, categories of distinction as individual characteristics, specific characteristics are attributed to individuals in order to distinguish them from other individuals. One example is the binary distinction between participants as men or women, for instance through linguistic distinctions, as well as the distinction between participants via individual characteristics such as age or migration experience. This becomes evident, for example, when participants are described as 'young Syrian men' (interview 11, lls. 508-509). This description refers to gender but also age and migration experience as characteristics of the described participants. Moreover, gendered attributions to individuals also emerge in gendered language: 'Here in Windland, it's unacceptable to speak of "Lehrer" [the generic masculine form in German]; mostly you will hear people say "Lehrpersonen" [the gender neutral form in German] or "Lehrerinnen und Lehrer" [the feminine and masculine form in German] (interview 3, 1ls. 460-464). The distinctions reconstructed for this analysis reveal an orientation towards participants as individuals, which is evident in attributions of individual distinctions.

The second pattern of reasoning, categories of distinction as characteristics for grouping individuals, strongly builds on the first pattern and can be understood as a somewhat more collective assumption. Categories of distinction are reconstructed as group-specific characteristics, for instance as characteristics of target groups distinguished by gender: 'We started marketing topics exclusively for women' (interview 13, lls. 774-775). The same pattern of reasoning emerges with respect to age as a category of distinction: 'I think that seniors simply want to stay active longer, that they are fitter and more enthusiastic than they used to be, and that they do not see themselves as the typical stay-at-home seniors' (interview 8, 1ls. 604-608). In the context of programme planning, the second pattern of reasoning refers to the distinction of groups based on categories of distinction attributed to them - categories that are essential for determining target groups.

The reconstruction of the third pattern of reasoning, categories of distinction as characteristics of shared expectations, builds on the previous pattern. In the underlying process of differentiation, the element of anticipated needs is formed by imputing shared expectations of groups. This emerges as a pattern for reasoning the categorisation of groups, based on categories of difference.

Typically, participants are mothers and their children; that is of course rather the social aspect of it $[. .$.$] how do I educate [. .$.$] an adventurous$ course, but one in which participants are fathers and their sons [...] experiencing nature together is the bait, so to speak, but what this is really about is a relationship, of course, fathers with their sons, or daughters, for all I care (interview 14, 1ls. 267-284).

In this example, programme planning is focused on a clear target group orientation based on the anticipated needs of women and men in their roles as mothers and fathers. This pattern of reasoning also emerges with respect to age: 'In the courses exclusively for seniors, I do respond to that by not putting a twenty-year-old instructor in front of them' 
(interview 8, 1ls. 689-692). The interviewee explains to choose instructors based on the target group, which is defined as seniors, by the category of age. When looking at migration experience as a category of distinction, the adjustment of course contents is justified by the assumption of shared needs: 'Our programme recently also included hiking excursions for new inhabitants and refugees' (interview 10, 1ls. 703-704). Here, the anticipated need is based on the joint exploration of the regional surroundings.

The fourth reconstructed pattern of reasoning entails categories of distinction as occupation- and employment-related characteristics. When it comes to the attribution of categories of distinction, the data reveals manifold references connected to developing and maintaining occupations and employment. Women as a distinct group, for example, are assumed to have a need for leadership courses specifically for women: 'You don't want them to get the impression [...] that leadership in Germany is frequently male [...] but to experience freedom in this protected space, women among women, equals among equals' (interview 12, 1ls. 277-280). The target groups, previously defined based on anticipated needs, are thus assumed to have a particularly strong need for integration into jobs and the labour market. Age-based distinctions are made in this pattern of reasoning by referring to people's work experience: 'I see the positive side, the older ones in particular, who of course are more experienced and can share their experiences with the younger ones; the younger ones [...] who come up with new ideas' (interview 11, lls. 482-485). Here, age as a category of distinction is connected in positive terms to different kinds of work experience. At the same time, this pattern of justification serves as the basis for anticipating occupation-specific needs with regard to migration experiences: '[...] explicitly for vocational school students with refugee backgrounds, actually more of a assessment of expectations with these vocational school students [...] what kind of support do I need to graduate from this vocational school and to successfully complete my vocational training as well' (interview 5, 1ls. 362-369).

The extent to which these patterns of justification for attributing categories of distinction occur varies by category. The three categories of distinction gender, age and migration experience can be centrally reconstructed based on the interview data. They are used for determining target groups, for developing specific courses, and for choosing instructors to teach these courses.

The analysis of the patterns of justification shows that programme planners attribute anticipated educational needs to these target groups. The attribution of needs and the orientation towards them in programme planning processes includes the intention to help these groups improve their social participation. Social participation, in this case, refers to both educational participation and participation in the labour market through employment. Programme planners anticipate the need for social participation that is to be promoted and realised by participating in adult education courses. This means that processes of differentiation are based on patterns of justification that aim for increasing social participation. The goal is to support target groups and to enable education. In this process, participants are also expected to be responsible for their own active involvement by self-identifying and responding as part of a target group, by recognising their needs in that scope, and by attending courses that match the anticipated needs and their respective expectations as alleged members of those groups. 


\section{Awareness of categories of distinction as an incentive for reflection}

The analysis of interview data shows that programme planners do reflect critically on the distinctions they use and the resulting categorisations. Thus, assumptions can be derived that there are opportunities for critical reflection on the risk that programme planners in adult and continuing education employ a deficit-based approach in their target group orientation. Given that the interviewees have been asked about their daily work as programme planners rather than the differentiation within their target group orientation, they show a strong ability for critical reflection, with some of them questioning their own constructions of difference during the interview. Despite this focus of the interviews, the aspect of social desirability cannot be ruled out as an influential factor for the data material. Nevertheless, the findings indicate an ability for reflection at the same time as raising the question about the importance that the interviewees assign to making those distinctions while reflecting on their own work as programme planners. The analysis of categories of distinction in programme planning raises various questions that call for further research: What is the role of organisational goals and requirements, such as making sure that courses are filled to capacity, when it comes to drawing on categories of distinction? Which societal factors prove themselves to be important in their interrelations with programme planning? How do the differentiations show in the programmes? And how does the intentional or unintentional use of categories of distinction relate to opportunities for professionalisation in adult education?

Raising these questions does not suggest that heterogeneity shall be 'dealt with' or 'managed'. Instead, the use of terms, as if they were some kind of tool, is one of the key aspects that need to be reconsidered critically when thinking of categories of distinction in programme planning. A critical potential is taking on a greater significance in the fact that attributions of the Other are recognised as fluid aspects of identity. Rather than managing these aspects with the help of competences, attributions should be reflected critically on a permanent basis. The main problematic with the idea of managing or dealing with something is that differences are understood as statistical characteristics, for instance as predefined sociodemographic characteristics or as dealing with something foreign such as foreign cultures. If this assumption in the management of differences is understood as an expanded form of intercultural competence, Othering processes clearly emerge as the basis of target group orientation.

By reflecting on categories of distinction, a critical examination between target group and participant orientation can be encouraged and a negotiation of the attribution of needs versus a recognition of expectations can be addressed. Raising an awareness for attributions of meaning and hierarchisations that arise with categories of differences by reflecting those processes can lead to a sensitisation for making distinctions. As a result, planning processes in programme planning and adult education might become more conscious and therefore more sensitive to inequalities that may arise from the construction of differences. 


\section{Notes}

${ }^{1}$ In the German context, there can be identified different concepts and argument of target group orientation which were mainly developed in the 1970s (Schiersmann, 2010; Siebert 2012). Arguments were e.g. homogenisation of learning groups), social-political orientation or bottom-up approaches. The concept is accompanied with critical reflection of a deficit attribution towards identified groups. In this paper, the term target group is understood from a didactical perspective, which can be seen as very common in adult education practice. According to Siebert (2012, p.111) target orientation assumes a "collective life situation" (translated by the authors, in German: "kollektive Lebenssituation"). Von Hippel et. al. (2019) argue that based on this assumption common educational needs and expectations are defined.

\section{References}

Allemann-Ghionda, C. (2013). Bildung für alle, Diversität und Inklusion: Internationale Perspektiven. Ferdinand Schöningh.

Ashcroft, B., Griffiths, G., \& Tiffin, H. (2013). Postcolonial studies: The key concepts (3rd ed.). Routledge.

Baader, M. (2013). Diversity Education in den Erziehungswissenschaften. 'Diversity' as a buzzword. In K. Hauenschild, S. Robak, \& I. Sievers (Eds.), Diversity Education. Zugänge - Perspektiven Beispiele (pp. 38-59). Brandes und Apsel.

Caffarella, R. S., \& Daffron, S. R. (2013). Planning Programs for Adult Learners: A Practical Guide. Jossey-Bass.

Cervero, R. M., \& Wilson, A. L. (1994). Planning Responsibly for Adult Education. Jossey-Bass.

Clarke, A. (2012). Situationsanalyse. Grounded Theory nach dem Postmodern Turn. Springer VS.

Egetenmeyer, R., Breitschwerdt, L., \& Lechner, R. (2019). From 'traditional professions' to 'new professionalism': A multi-level perspective for analysing professionalisation in adult and continuing education. Journal for Adult and Continuing Education, 25(1), 7-24.

Fleige, M., Gieseke, W., Hippel, A. von, Käpplinger, B., \& Robak, S. (2018). Einleitung. In M. Fleige, W. Gieseke, A. von Hippel, B. Käpplinger, \& S. Robak (Eds.), Programm- und Angebotsentwicklung in der Erwachsenen- und Weiterbildung (pp. 10-17). wbv.

Gieseke, W. (2003). Programmplanungshandeln als Angleichungshandeln. Eine realisierte Vernetzung in der Abstimmung von Angebot und Nachfrage. In W. Gieseke (Ed.), Institutionelle Innensichten der Weiterbildung (pp. 189-211). Bertelsmann.

Gieseke, W. (2018a). Programm und Angebot. In M. Fleige, W. Gieseke, A. von Hippel, B. Käpplinger, \& S. Robak (Eds.), Programm- und Angebotsentwicklung in der Erwachsenen- und Weiterbildung (pp. 18-27). wbv.

Gieseke, W. (2018b). Bedarf und Bedürfnisse. In M. Fleige, W. Gieseke, A. von Hippel, B. Käpplinger, \& S. Robak (Eds.), Programm- und Angebotsentwicklung in der Erwachsenen- und Weiterbildung (pp. 28-37). wbv.

Gieseke, W., \& Hippel, A. Von (2018). Programmplanung als Konzept und Forschungsgegenstand. In M. Fleige, W. Gieseke, A. von Hippel, B. Käpplinger, \& S. Robak (Eds.), Programm- und Angebotsentwicklung in der Erwachsenen- und Weiterbildung (pp. 38-51). wbv.

Hall, S. (2002). Introduction. Who needs identity? In S. Hall, \& P. Du Gay (Eds.), Questions of Cultural Identity (pp. 1-18). Sage Publications.

Hippel, A. von (2011). Programmplanungshandeln im Spannungsfeld heterogener Erwartungen: Ein Ansatz zur Differenzierung von Widerspruchskonstellationen und professionellen Antinomien. REPORT - Zeitschrift für Weiterbildungsforschung, 34(1), 45-60. http://www.die-bonn.de/id/9187

Hippel, A. von, Kulmus, C, \& Stimm, M. (2019). Didaktik der Erwachsenen- und Weiterbildung. Verlag Ferdinand Schöningh.

Hippel, A. von, Tippelt, R., \& Gebrande, J. (2018). Adressaten-, Teilnehmer- und Zielgruppenforschung in der Erwachsenenbildung/Weiterbildung. In R. Tippelt, \& A. von Hippel (Eds.), Handbuch Erwachsenenbildung/Weiterbildung (6th ed., pp. 1131-1148). Springer VS.

Kuhlen, C. (2021). Differenzierungspraktiken in der Erwachsenenbildung. Eine Situationsanalyse zu Diversity im Programmplanungshandeln. Peter Lang.

Lacan, J. (1968). The language of the self: The function of language in psychoanalysis. Johns Hopkins University Press.

Lutz, H., \& Wenning, N. (2001). Differenzen über Differenz - Einführung in die Debatten. Leske und Budrich. 
Prengel, A. (2013). Geleitwort: Diversität und Bildung. In K. Hauenschild, S. Robak, \& I. Sievers (Eds.), Diversity Education. Zugänge - Perspektiven - Beispiele (pp. 11-14). Brandes und Apsel.

Robak, S. (2013). Diversität in der Erwachsenenbildung(sforschung) im Spiegel theoretischer und empirischer Reflexionen - eine Standortdiskussion. In K. Hauenschild, S. Robak, \& I. Sievers (Eds.), Diversity Education. Zugänge - Perspektiven - Beispiele (pp. 183-203). Brandes und Apsel.

Robak, S. (2016). Zur Konzeptualisierung von Diversität in der Erwachsenenbildung und Weiterbildung: Begriffsentwicklung und empirische Ergebnisse aus den Bereichen Inter-/Transkultureller und Kultureller Bildung. In K. Dollhausen, \& S. Muders (Eds.), Diversität und Lebenslanges Lernen. Aufgaben für die organisierte Weiterbildung (pp. 27-45). wbv.

Siebert, H. (2012). Didaktisches Handeln in der Erwachsenenbildung. Didaktik aus konstruktivistischer Sicht (7th ed.). Ziel Verlag.

Schiersmann (2010). Zielgruppen. In R. Arnold, S. Nolda \& E. Nuissl (Eds.), Wörterbuch Erwachsenenbildung (2nd ed., pp. 321-323). Verlag Julius Klinkhardt.

Tippelt, R., \& Hippel, A.von (2018). Vorwort und Einleitung zur 6. überarbeiteten und erweiterten Neuauflage. In R. Tippelt, \& A. von Hippel (Eds.), Handbuch Erwachsenenbildung/Weiterbildung (6th ed., pp. 1-16). Springer VS.

Walgenbach, K. (2017). Heterogenität - Intersektionalität - Diversity in der Erziehungswissenschaft (2nd ed.). Barbara Budrich.

Witzel, A. (2000). Das problemzentrierte Interview. Forum Qualitative Sozialforschung, 1(1), Art. 22. http://nbn-resolving.de/urn:nbn:de:0114-fqs0001228

Zifonun, D. (2018). Deuten und Handeln, Kategorie und Gruppe, Kategorisierung, Klassifikation und Typisierung $-\mathrm{Zu}$ einem (nicht nur) methodischen Problem (nicht nur) der Ethnographie der Migration und der Ethnizität. In N. Burzan, \& R. Hitzler (Eds.), Typologische Konstruktionen. Prinzipien und Forschungspraxis (pp. 79-94). Springer VS. 